\title{
SELF TUNING OF CLASS H INDUCTION MOTOR FIELD ORIENTED CONTROL
}

\author{
H. M. El-shewi*, F. E. Abdel-kader**, H. M. Metwally*, S. I. Selem* \\ * Department of Electrical power and machines, Faculty of Engineering, Zagazig University \\ ** Department of Electrical Engineering, Faculty of Engineering, Minoufiya University
}

\begin{abstract}
In this paper the steady state characteristics of a self tuned field oriented control induction motor drive are presented. The induction motor will be self tuning after one or more of its parameters varied. Both basic types of field oriented control have some sensitivity to machine parameters and provide non-ideal torque control characteristics when control parameters differ from actual machine parameters. In general, both steady state torque control and dynamic response differ from the ideal instantaneous torque control achieved by a correctly tuned controller.

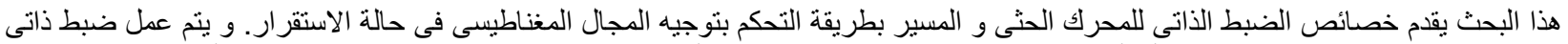

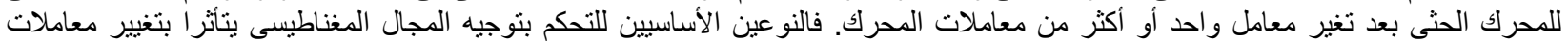

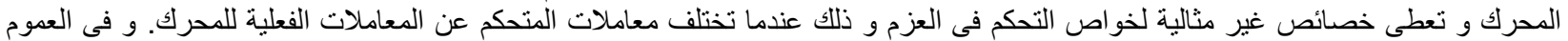
فإن التحكم العزمى فى حالة الإستقرار و الإستجابة الديناميكية تختلف عن التحكم اللحظى المثالى و الذى يتم عن طريق القيم الصحيحة للمتحكم المضبوط.
\end{abstract}

Keywords: Induction motor, Class H, field oriented control, parameter variation, Self tuning

\section{INTRODUCTION}

Field oriented control (FOC) or vector control (VC) has made a fundamental change with regard to dynamic performance of induction machines (IM). Vector control makes it possible to control induction motor in a manner similar to control scheme used for the separately excited dc motor. But both basic types of field oriented control have some sensitivity to machine parameters and provide non-ideal torque control characteristics when control parameters differ from actual machine parameters.

In indirect FOC, the major problem is the rotor time constant which is sensitive to both temperature and flux level. When this parameter is incorrect in the controller the calculated slip frequency is incorrect and the flux angle is no longer appropriate for the field orientation. This results in an instantaneous error in both flux and torque. There is also a steady state torque error since the steady state slip is also incorrect. In addition steady state slip error cause additional motor heating and reduce efficiency.
Direct field oriented (DFO) systems are generally sensitive to stator resistance and total leakage but the various systems have individual detuning properties. Typically, parameter sensitivity is less than in indirect field orientation (IFO), especially when a flux regulator is employed. In all cases, for both IFO and DFO, large high efficiency machines tend to have high sensitivity to parameter errors and field weakening operation further enhance this sensitivity. Typically, parameter sensitivity in small machines is low enough that regarding problems are less serious.

Vas [1] concluded that if incorrect modulus and angle of the flux-linkage space vector are used in a vector control scheme, then flux and torque decoupling is lost and the transient and steady state responses are degraded. Low frequency response, speed oscillations, and loss of input-output torque linearity are major consequences of detuned operation, together with decreased drive efficiency.

If one or more parameter is varied, this will produce errors in the rotor position. Since the angle is used for 
field orientation, it is clear that the Park transformation is done with an incorrect angle. The immediate consequence is that the torque dynamics is compromised. The d-q currents are not correctly aligned to the real rotor flux vector. The attempt to regulate one of the currents will change the other one and vice-versa (decoupling is lost). The torque produced suffers and the speed dynamics may show oscillations or even instability depending on how large the angle error is.

Since most methods require the knowledge of machine parameters, many research efforts are focused on robust control that not depends on parameter variations of induction machines. In [2] a new stator current sensorless position-flux tracking control algorithm, which is robust to electrical motor parameter variations, is presented. The salient advantage of the observer [3] is that it does not need the information of any machine parameter. From simulation results, fuzzy logic control (FLC) is more robust to parameter variation [4]. The proposed adaptive fuzzy sliding mode control [5] has the advantage of online adaptation ability to handle the plant variations or changing environments. Also a FLC based on-line continuous tuning method of slip gain of FOC IM drive has been proposed [6]. In order to counter parameter sensitivity issue and to develop more robust control method, reference [7] proposes a self tuning adaptive control strategy for VC IM drives. The proposed methodology in [8] shows that exact electrical and mechanical models of the induction motor are not necessary. Online self tuning neural network (NN) controller for induction motor drives was presented [9].

The impact of parameter variations has been studied in detail. The consequence of any mismatch between the parameter values used in the controller and those in the motor is that the actual rotor flux position does not coincide with the position assumed by the controller. Therefore the drive performance is wrong, and it is necessary to update the parameter values. Parameters estimation can be done by means of measuring, in the drives initialization, or by tests based on an inverter supply as in the off-line parameter identification. On the other side, there exist methods to update the parameters value during the drive operation. In [10] the two-layered neural estimator is used to provide a realtime adaptive estimation of IM unknown parameter. Online parameter estimation has been proposed [11]. Estimation of stator and rotor resistances and rotor leakage inductance taking thermal and skin effect (for rotor resistance only) in IFOC has been presented [12]. In [13], two techniques have been demonstrated, one which requires no a priori knowledge of the machine to allow online estimation of all the required electrical parameters and a second technique which eliminates the need for signal injection at the expense of requiring an offline estimate of the stator transient inductance. Automatic tuning machine parameter estimation schemes has been presented [14], [15]. Automatic tuning of stator resistance and inductance as well as rotor resistance and inductance has been proposed [16]. In [17] four schemes for the real-time identification of the rotor and stator resistances of IM based on the MRAS approach are proposed.

\section{INDIRECT VECTOR CONTROL}

In this section, the indirect vector controller is derived from the dynamic equations of the induction machine in the synchronously rotating reference frames. The rotor equations of the induction machine are given by:

$$
\begin{aligned}
& R_{r} i_{q r}^{e}+p \lambda_{q r}^{e}+\omega_{s l} \lambda_{d r}^{e}=0 \\
& R_{r} i_{d r}^{e}+p \lambda_{d r}^{e}+\omega_{s l} \lambda_{q r}^{e}=0
\end{aligned}
$$

Where

$$
\begin{aligned}
& \omega_{s l}=\omega_{s}-\omega_{r} \\
& \lambda_{q r}^{e}=L_{m} i_{q s}^{e}+L_{r} i_{q r}^{e} \\
& \lambda_{d r}^{e}=L_{m} i_{d s}^{e}+L_{r} i_{d r}^{e}
\end{aligned}
$$

In this equations, $R_{r}$, the referred rotor resistance per phase; $L_{m}$, the mutual inductance per phase; $L_{r}$, the referred rotor self inductance per phase; $i_{d r}^{e}$ and $i_{q r}^{e}$, the referred direct and quadrature axes currents respectively; $i_{d s}^{e}$ and $i_{q s}^{e}$, the stator direct and quadrature axes currents respectively; $p$, the differential operator; $\omega_{s l}, \omega_{s}$ and $\omega_{r}$, slip speed, synchronous speed and electrical rotor speed in $\mathrm{rad} / \mathrm{sec}$, and $\lambda_{d r}^{e}$ and $\lambda_{q r}^{e}$ are rotor direct and quadrature axis flux linkages. Aligning the d-axis with rotor flux phasor yields: 


$$
\begin{aligned}
& \lambda_{r}=\lambda_{d r}^{e} \\
& \lambda_{q r}^{e}=p \lambda_{q r}^{e}=0
\end{aligned}
$$

Substituting equations (6) and (7) in (1) and (2) and using equations (4) and (5), the followings are obtained:

$$
\begin{aligned}
& i_{f}=i_{d s}^{e}=\frac{\lambda_{r}}{L_{m}}\left(1+p T_{r}\right) \\
& i_{t}=i_{q s}^{e}=\frac{\lambda_{r}}{L_{m}} T_{r} \omega_{s l}
\end{aligned}
$$

Where $T_{r}$ the rotor time constant and equal to:

$$
T_{r}=L_{r} / R_{r}
$$

The q- and d-axis currents are labeled as torque and flux producing components of the stator current phasor, respectively. The induction machine torque equation can be obtained as:

$$
T_{e}=\frac{3}{2} \frac{P}{2} \frac{L_{m}}{L_{r}}\left(\lambda_{r} i_{q s}\right)=\frac{3}{2} \frac{P}{2} \frac{L_{m}}{L_{r}} \lambda_{r} i_{t}=K_{t} \lambda_{r} i_{t}
$$

Where $K_{t}$ is torque constant and equal to:

$$
K_{t}=\frac{3}{2} \frac{P}{2} \frac{L_{m}}{L_{r}}
$$

From previous equation, it can be noted that, the torque is proportional to the product of the rotor flux linkages and the stator q-axis current. This resembles the torque expression of dc motor, which is proportional to the product of the field flux linkages and the armature current. If the rotor flux linkage is kept constant, then the torque is simply proportional to the torque producing component of the stator current $\left(i_{t}\right)$, as in the case of the separately excited dc machine.

\section{SIMULATION RESULTS}

A matlab program is developed based on the equations of the induction motor in FOC; this program calculates and plots the characteristics of class $\mathrm{H}$ induction motor. In this class, the maximum allowable increase in temperature is $130^{\circ} \mathrm{C}$ for a room temperature of $40^{\circ} \mathrm{C}$ and the temperature coefficient of a copper at $40^{\circ} \mathrm{C}$ is 0.00364 , so the new resistance due to increase in temperature (maximum) can be calculated as follow

$$
R_{n}=R_{o}(1+0.00364 * 130)=1.4832 * R_{o}
$$

Where $R_{o}$ and $R_{n}$ are the original and new resistance due to temperature increase.

In Figure (1), R1o and R2o are the original stator and rotor resistances respectively at room temperature, and $\mathrm{R} 1 \mathrm{n}$ and $\mathrm{R} 2 \mathrm{n}$ are the new stator and rotor resistances respectively at maximum temperature at which the IM can operate.

In all the next figures, there are three cases as the following:

Case 1: Field oriented control with no parameter variation in solid line.

Case 2: Detuned field oriented control with parameter variation in dotted line

Case 3: Well tuned field oriented control with parameter variation in dashed line

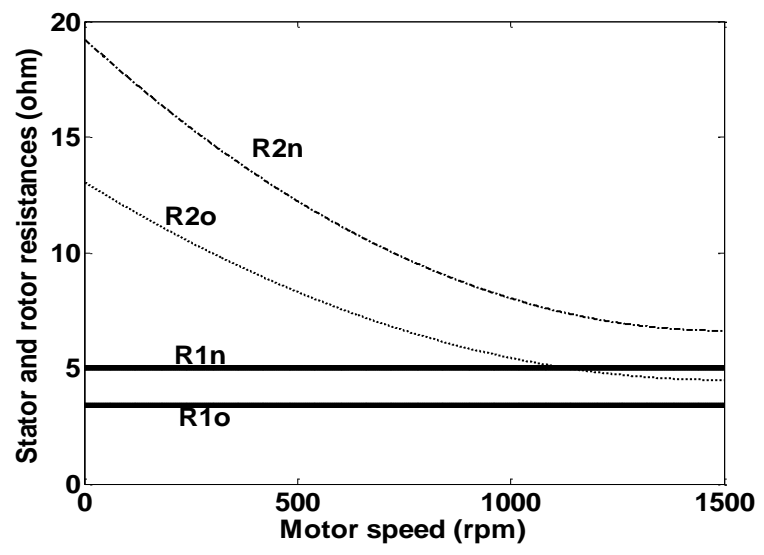

Fig. (1) Variation of stator and rotor resistance with speed 


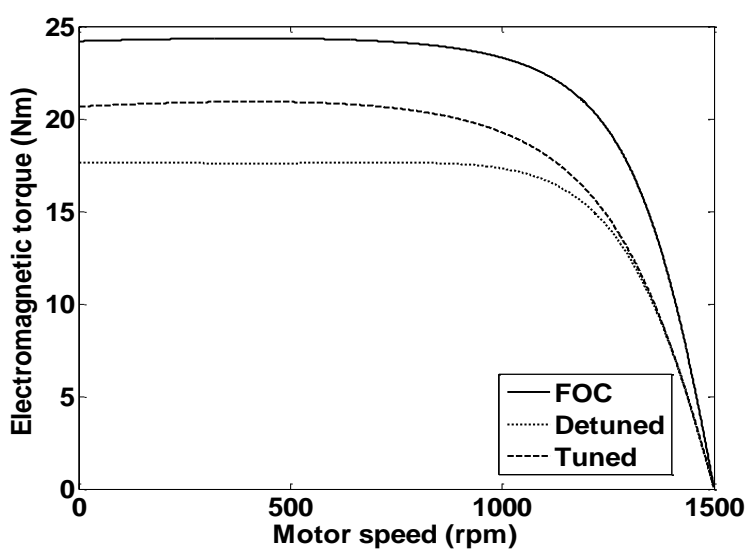

Fig.(2) Variation of motor torque with speed

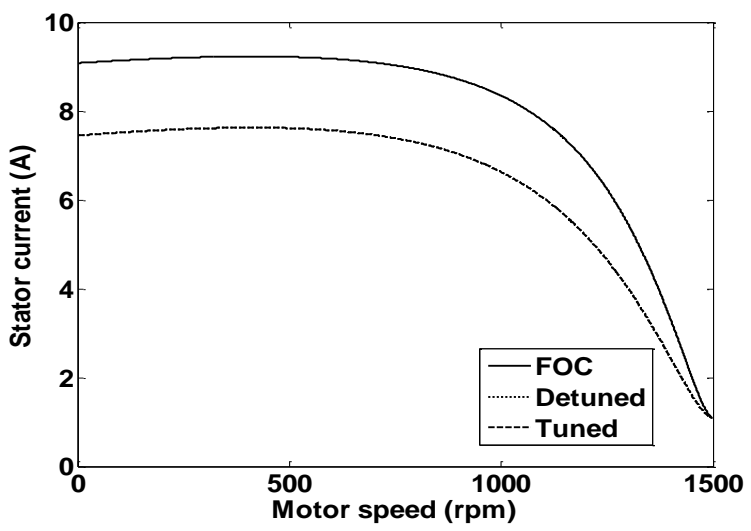

Fig. (3) Variation of stator current with speed

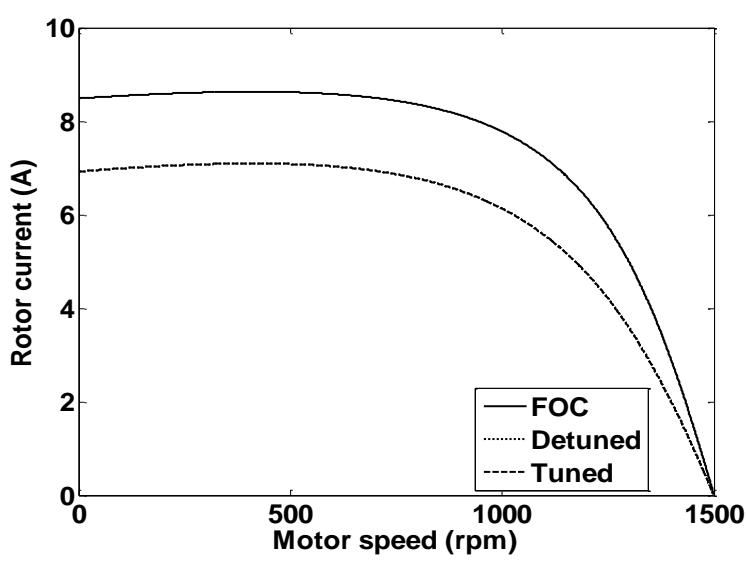

Fig. (4) Variation of rotor current with speed

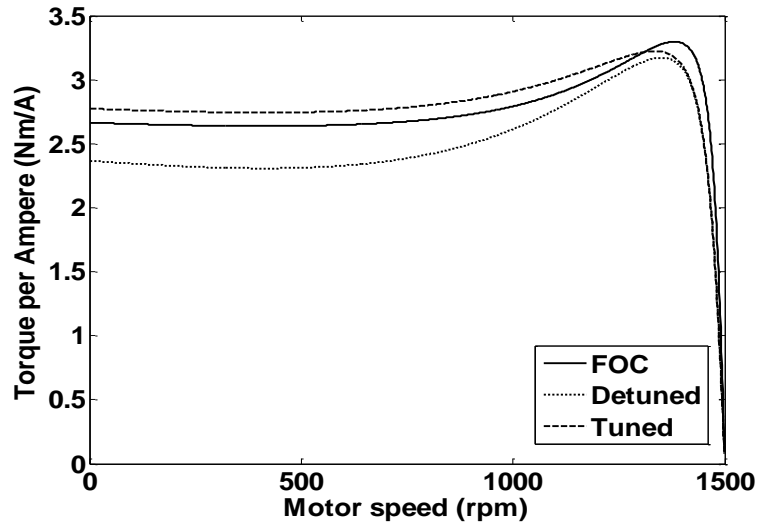

Fig. (5) Variation of torque per ampere with speed

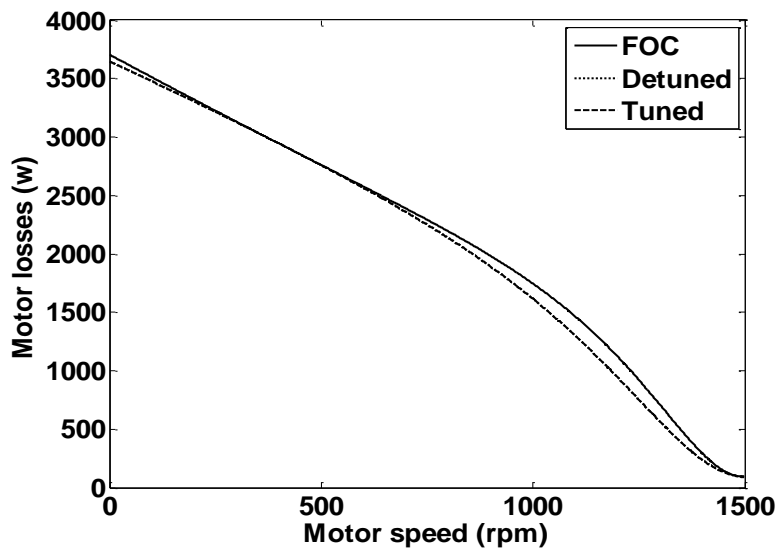

Fig. (6) Variation of motor losses with speed

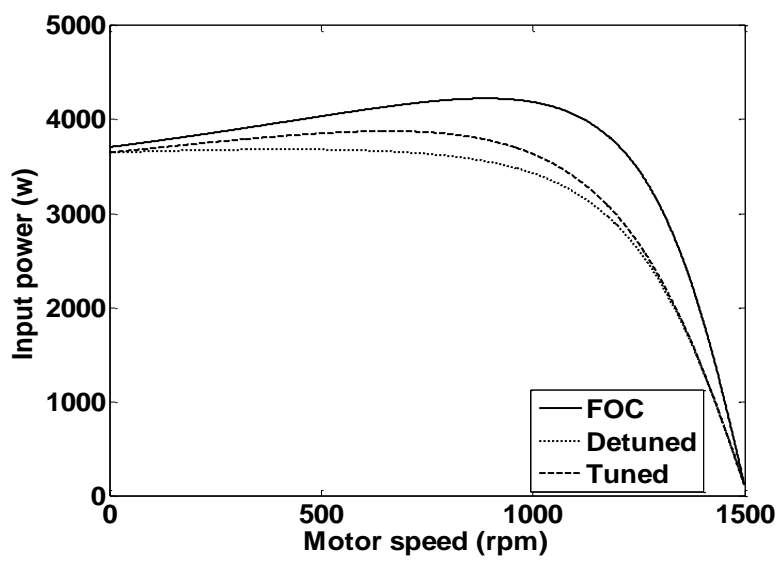

Fig. (7) Variation of input power with speed 


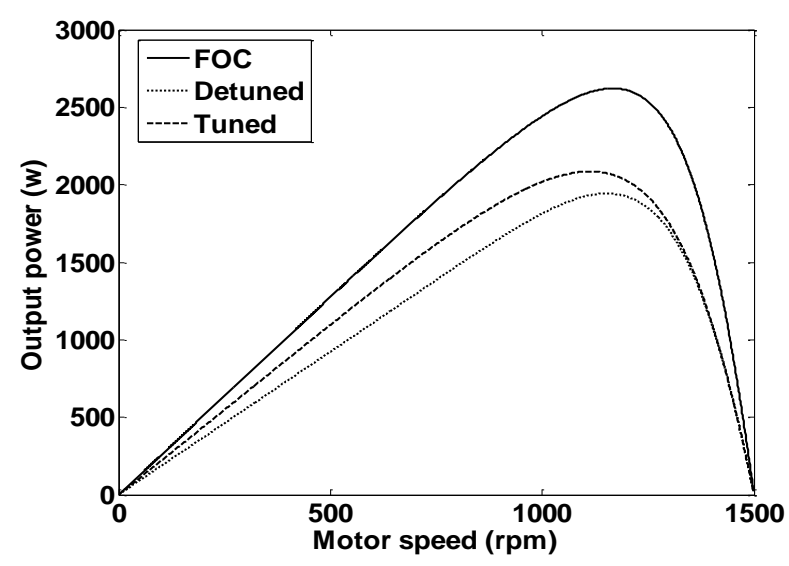

Fig. (8) Variation of output power with speed

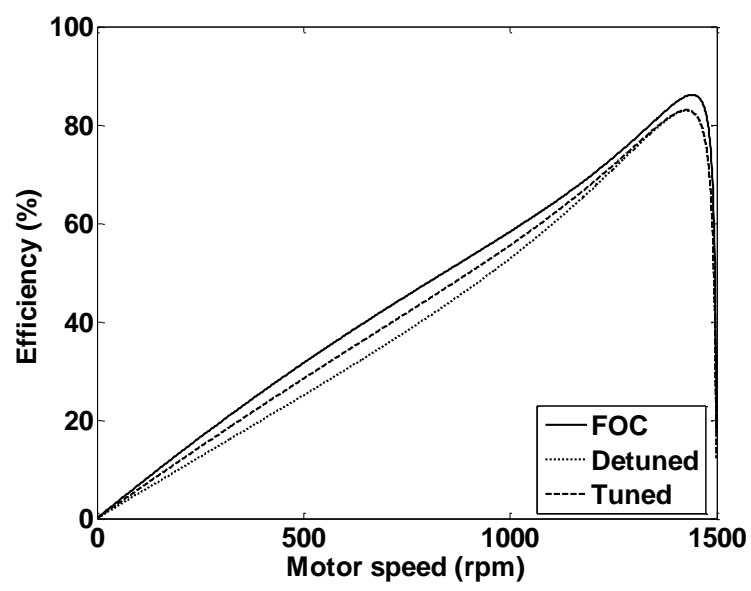

Fig. (9) Variation of motor efficiency with speed

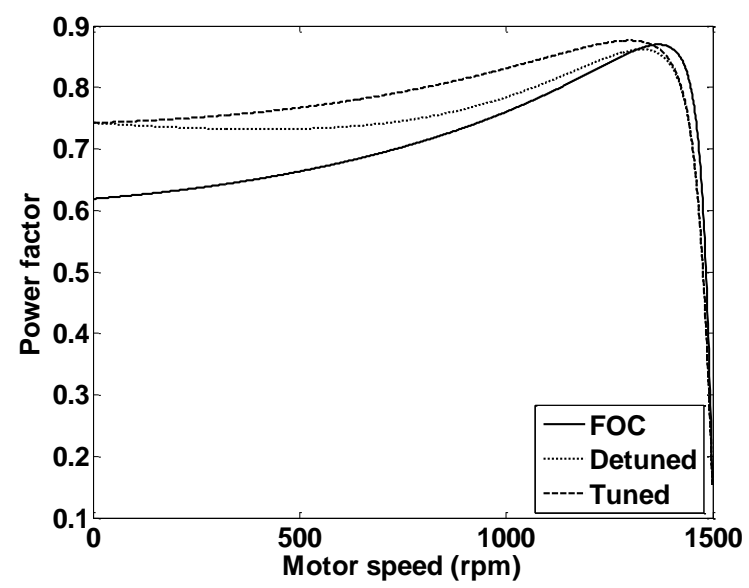

Fig. (10) Variation of motor power factor with speed

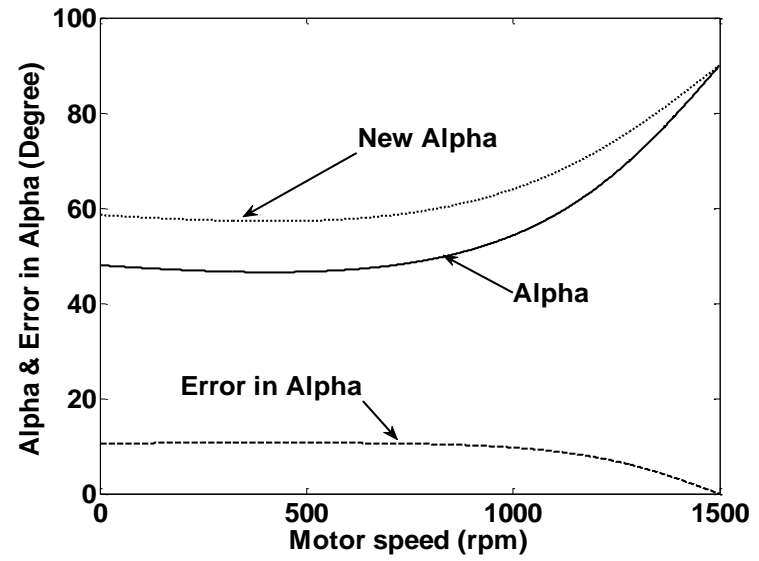

Fig. (11) Variation of delayed and advanced angles with speed

From Fig. (2), the starting torque for detuned case is decreased by $27.13 \%$ of its original value, but for tuned case this decrease is $14.61 \%$. The difference between original, tuned and detuned torques is decreased as the speed increase. For the same stator current in detuned and tuned cases, the starting torque of tuned case increased by $17.19 \%$ of that for detuned.

When the motor temperature is increased the stator and rotor resistances are increased, thus reducing the stator and rotor currents for both detuned and tuned cases as shown in Figures (3) and (4).

From Fig. (3), the starting stator current for detuned and tuned cases is decreased by $17.97 \%$ of its original value. The difference between original and new stator currents is decreased as the speed increase.

From Fig. (4), the starting rotor current for detuned and tuned cases is decreased by $18.42 \%$ of its original value. The difference between original and new rotor currents is decreased as the speed increase.

From Fig. (5), the starting torque per ampere for detuned case is decreased by $11.17 \%$ of its original value, but for tuned case it increased by $4.1 \%$. The difference between original, detuned and tuned torque per ampere is decreased as the speed increase. For the same stator current in detuned and tuned cases, the starting torque per ampere of tuned case increased by $17.19 \%$ of that for detuned case. 
From Fig. (6), the motor losses for detuned and tuned cases are less than that of original losses.

From Fig. (7), the difference between tuned and original input power is smaller than that between detuned and original. For stable region, the difference between original, tuned and detuned input power is decreased as the speed increase, and the difference between tuned and detuned input power is very small.

From Fig. (8), the difference between tuned and original output power is smaller than that between detuned and original. For stable region, the difference between original, tuned and detuned output power is decreased as the speed increase, and the difference between tuned and detuned output power is very small.

From Fig. (9), the difference between tuned and original efficiency is smaller than that between detuned and original. For stable region, the difference between original, tuned and detuned efficiency is decreased as the speed increase, and the difference between tuned and detuned input power is very small.

From fig. (10), the starting power factor of tuned and detuned cases is the same and its value is higher than that of original one. For stable region, the difference between tuned, original and detuned power factor is decreased as the speed increase, and the difference between tuned and detuned power factor is very small.

From fig. (11), the actual angle is increased by $22.01 \%$ of its original value. This difference is decreased as the speed increase.

\section{CONCOLUSION}

A self tuned class $\mathrm{H}$ induction motor is presented. The effect of temperature increase on the value of stator and rotor resistance is taken into account. In addition, the skin effect is taken into account for rotor resistance. The performance characteristics of motor are explored for original, detuned and tuned cases. The motor will be detuned if any one or more of its parameter vary. The performance under detuned is sluggish and to improve it, the motor has to be self tuned. The characteristics of tuned motor are better than that of detuned one.

\section{Appendix}

Induction motor details:

$$
\begin{aligned}
& 2 \mathrm{Hp}, 380 \mathrm{v}, 4-\text { pole, } 50 \mathrm{~Hz}, R_{s}=3.41 \Omega, \\
& R_{r}=4.5+8.57 \mathrm{~S}^{2} \Omega, X_{s}=7.37 \Omega, X_{r}=11.77 \Omega, \\
& X_{m}=195 \Omega, R_{m}=1700 \Omega
\end{aligned}
$$




\section{REFERENCES}

[1] P. Vas, "Sensorless Vector and Direct Torque Control", Oxford University Press, 1998

[2] Marcello Montanari, Sergei Peresada, Carlo Rossi, and Andrea Tilli, "Current Sensorless Position-Flux Tracking Controller for Induction Motor Drives", Mechatronics, Vol. 17, No. 1, pp. 15-30, February 2007.

[3] Z. S. WANG, S. L. HO, and E. K. W. CHENG, "Adaptive Rotor Flux Position Observer in the Absence of Machine Parameter Information for Vector Controlled Induction Motor Drives", Electric Power Components and Systems, Vol. 33, No. 7, pp. 801818,2005

[4] Libor Stepanec, and Pavel Brandstettee, "Fuzzy Logic in Vector Controlled Induction Motor Drive", EPE 2003 - Toulouse

[5] Chih-Min Lin, and Chun-Fei Hsu, "Adaptive Fuzzy Sliding-Mode Control for Induction Servomotor Systems", IEEE Transactions on Energy Conversion, Vol. 19, No. 2, pp. 362-368, June 2004

[6] Gilberto C. D. Sousa, Bimal K. Bose, and Kyung S. Kim, "Fuzzy Logic Based On-line MRAC Tuning of Slip Gain for an Indirect Vector-Controlled Induction Motor Drive", Proceeding of the International Conference on Industrial Electronics, Control, and Instrumentation, IECON, Vol. 2, pp.1003-1008, 15-19 Nov.1993, Maui, Hi

[7] Yao-Tze Kao, Yumg-Chang Luo, and Chang-Huan Lui, "Design and Implementation of a Self-Tuning Adaptive Controller for Vector Controlled Induction Motor Drives", Proceeding of the IEEE International Symposium on Industrial Electronics, Vol. 2, pp. 639642, 25-29 May1992, Xian

[8] Q.M.Zhu, L.Z.Guo, and Z.Ma "Neural Network Enhanced Optimal Self-tuning Controller Design for Induction Motors", Nonconvex Optimization and its Applications, Vol. 85, pp. 529-546, 2006

[9] Won Seok Oh, Bimal K. Bose, Kyu Min Cho, and Hee Jun Kim, "Self Tuning Neural Network Controller for Induction Motor Drives", IEEE $28^{\text {th }}$ Annual conference of the Industrial Electronics Society, IECON, Vol. 1, pp. 152-156, 5-8 Nov. 2002
[10] Tsong-Terng Sheu, and Tien-Chi Chen, "Selftuning Control of Induction Motor Drive Using Neural Network Identifier", IEEE Transactions on Energy Conversion, Vol. 14, No. 4, pp. 881-886, December 1999

[11] T. C. Green, M. W. Dunnigan, D. Holliday, S. Wade, and B. W. Williams, "Measurement and On-line Estimation Approaches to Parameter Variation in Vector Controllers", IEE Colloquium on Developments in Real-Time Control for Induction Motor Drives, 2 Feb. 1993, London

[12] Mario J. Duran, Jose L. Duran, Francisco Perez, and Jose Fernandez, "A Novel Sensorless Rotor-FluxOriented Control Scheme with Thermal and Deep-Bar Parameter Estimation", Book Chapter, pp. 165-176, 2006

[13] D. Telford, M. W. Dunnigan, and B. W. Williams, "Online Identification of Induction Machine Electrical Parameters for Vector Control Loop Tuning", IEEE Transactions on industrial electronics, Vol. 50, No. 2, pp. 253-261, April 2003

[14] Soshin K., Ahmed T., Nakaoka M., and Okamura Y., "Sensor-less Speed Control Strategy for Induction Motor Drive Incorporating Vector Controlled Scheme PWM Inverter-Fed with Auto-Tuning Machine Parameter Estimation", The 29 $9^{\text {th }}$ Annual Conference of the IEEE Industrial Electronics Society, IECON, Vol. 2, pp. 1721-1726, 2-6 Nov. 2003

[15] Ben-Brahim L., Gastli A., and Al-Hamadi M.A., "Auto-Tuning for Sensorless AC Motor Drive Systems", Proceedings of the IEEE International Symposium on Industrial Electronics, ISIE, Vol. 1, pp. 367-372, 12-16 Jul 1999, Bled

[16] Koji Soshin, Yukihiko Okamura, and Tarek Ahmed, "High Performance Sensor-less Induction Motor Drive Incorporating Vector Controlled Scheme PWM Inverter-Fed with Auto-Tuning Machine Parameter", EPE 2003 - Toulouse

[17] A.V. Pavlov, and A.T. Zaremba, "Real-Time Rotor and Stator Resistances Estimation of an Induction Motor", Proc. Of the $5^{\text {th }}$ IFAC Symposium on Nonlinear, 2001 